\title{
Photodegradation of 17 $\alpha$-Ethynylestradiol (EE2) in the Presence of Humic Acid and Carbonate Ions in Water Solutions
}

\author{
Faten Albalawi and Yuegang Zuo
}

\begin{abstract}
The concerns over 17a-ethynylestradiol (EE2) have been growing in the recent years due to its increasing presence in the environment and its high estrogenic potency. However, there is a limited amount of research available on the photochemical behaviors of EE2 in the presence of various aquatic environmental matrix components even though photodegradation has been considered an effective pathway for the removal of organic pollutants from not only waste waters but also natural aquatic ecosystems. Herein, the direct photodegradation of EE2 and the effects of common natural water matrix components, humic acid and carbonate ions, on the photodegradation were studied. High-Performance Liquid Chromatography (HPLC) was utilized to determine the concentrations of EE2. The direct photodegradation of EE2 was found to increase with increasing water $\mathrm{pH}$ value in the range of 7.0 to 10.0 and the photodegradation rate constant increased with increasing concentration of EE2. Humic acid enhanced the photodegaradation rate of EE2 under the simulated sunlight employed, while carbonate $\left(\mathrm{CO}_{3}{ }^{2-} / \mathrm{HCO}_{3}{ }^{-}\right)$ had shown slight influences on EE2 photodegradation.
\end{abstract}

Index Terms-17a-Ethynylestradiol (EE2), concentration and pH influences, photodegradation, humic acid, carbonate.

\section{INTRODUCTION}

The detection of steroid estrogens (SE's) in the environment has shown increasing estrogenic levels in recent years, which has minatory effects for human and wildlife endocrine systems [1], [2]. The steroid estrogens have been considered being the most powerful endocrine disrupting chemicals (EDCs) as these exogenous substances can modify the performance of the endocrine system of an organism or its offspring [2], [3]. The sources for these chemicals include the residues from pharmaceutical medication for the treatment of prostate and breast cancer, hormonal replacement therapies, and hair lotions for antagonistic alopecia [1]-[3]. Several reports have been related EDC pollution in the environment to the development of abnormalities in male reproductive systems, the growth of fish, and stunted growth of wildlife animals [3]. The most commonly found estrogens in wastewater and natural waters are estrone (E1), 17ß-estradiol (E2), and estriol (E3) and 17 $\alpha$-ethynylestradiol (EE2). The synthetic estrogen $17 \alpha$-ethynylestradiol (EE2) (Fig. 1) is a main active ingredient in some oral contraceptives and is much more potent even at a concentration as low as $0.1 \mathrm{ng} \mathrm{L}^{-1}$. EE2 is more stable in aquatic environments than natural

Manuscript received February 9, 2018; revised March 30, 2018.

The authors are with the Department of Chemistry \& Biochemistry, University of Massachusetts Dartmouth, 285 Old Westport Road, North Dartmouth, MA 02747, United States (e-mail: falbalawi@umassd.edu). estrogens E1, E2, and E3. Biodegradation of EE2 in the natural environment was found to be much slower than its direct and indirect photodegradation [4], [5]. The half-life of EE2 biodegradation was found to be weeks or months under most natural water conditions [5]. It is important for environment scientists to examine the concentration of the estrogenic hormones and their fate in natural water to understand the toxic effect of estrogens on aquatic organisms [1], [2], [6]. One of the effective way used to remove the organic pollutants from the environment is photodegradation. The half-life of EE2 photodegradation was determined to be hours in natural surface waters [1], [7], [8]. Since the half-life of EE2 for biodegradation are weeks and months, so photodegradation may play a more important role in the environmental fate of EE2. The rapid photodegradation of organic pollutants in natural waters was always attributed to the acceleration effects of a number of organic and inorganic chromophores [1], [9]-[13]. Humic acid, a main ingredient of humic substances in natural water, has a significant effect on the photochemical processes in natural aquatic environments. It is important to explore the influences of humic acid on the photodegradation of E22 to predict the transport and fate of this organic contaminant in natural water. Carbonate and bicarbonates, which are responsible for alkalinity, are ones of the most common inorganic salts present in natural surface water and may affect aquatic photochemical processes [10], [11]. But little research has studied the effect of $\mathrm{CO}_{3}^{-2} / \mathrm{HCO}_{3}^{-}$on the photodegradation of EE2. There are many studies ongoing on the photodegradation of estrogen E1, E2 and E3 during the last 15 years but the information on the photodegradation of EE2 is still limited [1], [4], [9], [10]. In this study, we first investigated the direct photodegradation of EE2 at various $\mathrm{pH}$ values with different initial substrate concentrations since $\mathrm{pH}$ is one of the important parameters that may influence reactive oxygen species formation and change the speciation of EE2. Then we examined the effects of humic acid and carbonate on the photodegradation of EE2.

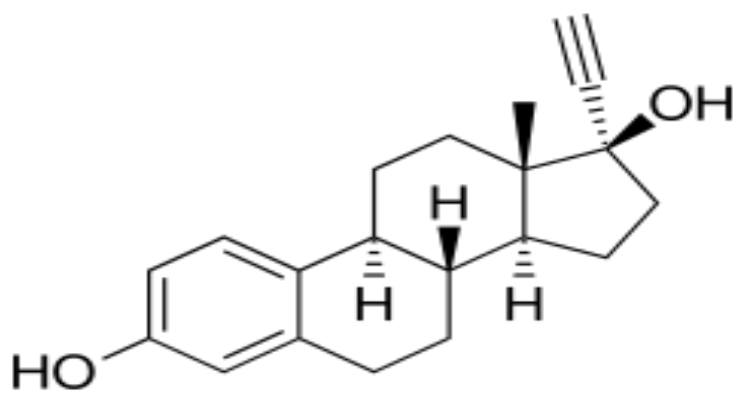

Fig. 1. Chemical structure of EE2. 


\section{MATERIALS AND METHODS}

\section{A. Materials}

Synthetic estrogen 17 $\alpha$-ethynylestradiol (EE2) was purchased from Sigma Aldrich (St. Louis, MO, USA). Disodium hydrogen phosphate and sodium perchlorate were purchased from Acros Organics (Geel, Belglum, NJ). Acetonitrile was HPLC grade, purchased from Pharmco Products (Brookfield, CT) and Fisher Scientific (Fair Lawn, NJ). Humic acid was purchased from Aldrich (Milwaukee, WI). Sodium chloride was purchased from Fisher Scientific (Fair Lawn NJ). Sodium bicarbonate was purchased from EM Science (Gibbstown, NJ). Methanol was obtained from Pharmco Products (Brookfield, CT). Except where noted, all reagents were of analytical grade and all solution preparations were made using doubly distilled-deionized water.

\section{B. Solution Preparation}

For complete dissolution of EE2, the EE2 solution was stirred for 24 hours at $20{ }^{\circ} \mathrm{C}$. A $10 \mathrm{mM}$ of either $\mathrm{NaClO}_{4}$ or $\mathrm{NaH}_{2} \mathrm{PO}_{4}$ was used as buffer solution in the experimentation. Initial $\mathrm{pH}$ of working solutions was adjusted using $\mathrm{NaOH}$ and $\mathrm{HClO}_{4}$. For photodegradation experiments EE2 solutions were prepared and stirred overnight at room temperature in dark before irradiation experiments were initiated.

\section{Photolysis Experiments}

Photochemical experiments were performed in capped 60 $\mathrm{mL}$ Pyrex glass photolysis tubes along with a $150 \mathrm{~W}$ Xenon Short Arc lamp as a light source (Newport Oriel Instruments, Stamford, CT, USA). The irradiation intensity of the illumination source was regulated via voltage control. A Thermo-Scientific Evolution 60 model Ultraviolet (UV) Spectrophotometer was employed to record UV-visible spectra.

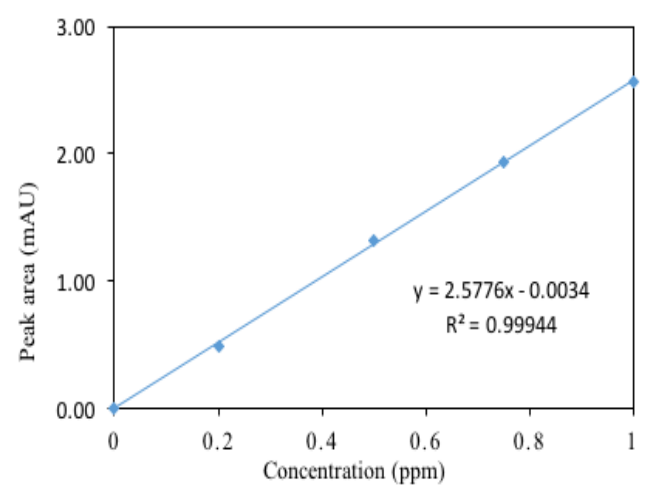

Fig. 2. Calibration curve of $17 \alpha$-ethynylestradiol (EE2).

\section{Analytical Method}

A Thermo-Scientific HPLC apparatus Dionex Ultimate 3000 was used for the determination of concentration of EE2 with the aid of a diode array detector. The separations were achieved on the YMC-Pack Pro C18 reversed phase column having dimensions as $150 \times 4.6 \mathrm{~mm}$, and particle specifications as $3 \mu$ and $120 \mathrm{~A}$. A mixture of acetonitrile and $\mathrm{H}_{2} \mathrm{O}$ comprised of $60: 40$ ratio served as the mobile phase in the HPLC separation. The mobile phase flow rate was set at $0.8 \mathrm{~mL} / \mathrm{min}$ and the wavelength for detection was set at $280 \mathrm{~nm}$.

The analytical calibration curve for EE2 was established by analyzing of EE2 standard solutions with concentrations ranged from 0.200 to $1.00 \mathrm{ppm}$. The calibration curves were found to be linear as shown in Fig. 2 and the calibration equation is:

$$
\begin{gathered}
y=2.5776 x-0.0034 \\
R^{2}=0.99944
\end{gathered}
$$

\section{RESUlTS AND DisCUSSION}

\section{A. Direct Photodegradation}

Direct photodegradation of EE2 was performed with various initial concentrations of EE2 at different $\mathrm{pH}$ values to test the effects of these parameters on the degradation

\section{B. A.1. Kinetics for Direct Photodegradation of EE2}

When the photodegradation experimental results are plotted in the form $\ln \left(\mathrm{C} / \mathrm{C}_{0}\right)$ as a function of reaction time, a linear relationship is obtained (Fig. 3). This is in agreement with the theory of photochemical kinetics [12].

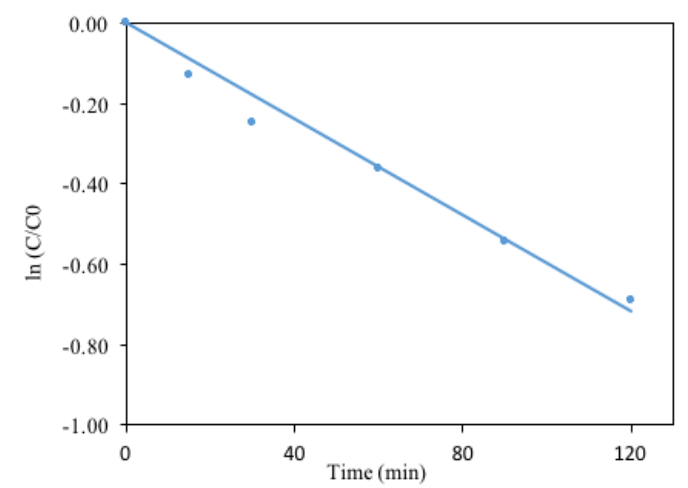

Fig. 3. First kinetic plot for the photodegradation of $17 \alpha$ ethynylestradiol (EE2) in water solution under simulated sunlight. [EE2 $]_{0}=0.20 \mathrm{ppm}, \mathrm{pH}=$ 8.0.

The photodegradation rate of EE2 at a given wavelength $\lambda$ can expressed by

$$
-\left(d \mathrm{C}_{\mathrm{EE} 2} / d \mathrm{t}\right)_{\lambda}=\phi_{\lambda} \mathrm{I}_{0 \lambda}\left(1-10^{-\varepsilon}{ }_{\lambda}^{\mathrm{CD}}\right)(\mathrm{S} / \mathrm{V}),
$$

where: $d \mathrm{C}_{\mathrm{EE} 2} / d \mathrm{t}$ is the average rate for the disappearance of EE2 $\left(\mathrm{M} \mathrm{s}^{-1}\right) ; \phi_{\lambda}$ is the quantum yield of the reaction; $\mathrm{I}_{0 \lambda}$ is the intensity of light incident to the reactor tube (Einstein $\left.\mathrm{cm}^{-2} \mathrm{~s}^{-1}\right)$; $\mathrm{S}$ is the area of the reactor exposed to light $\left(\mathrm{cm}^{2}\right)$; $\mathrm{V}$ is the reactor volume (liter); $\varepsilon_{\lambda}$ and $\mathrm{C}$ are the molar absorptivity $\left(\mathrm{M}^{-1} \mathrm{~cm}^{-1}\right)$ and concentration $(\mathrm{M})$, respectively, of the photochemical reactant EE2; and D is the light pathlength $(\mathrm{cm})$.

In natural water systems, chemical pollutants, like EE2, are generally present at low concentration, and only weakly absorb sunlight. When the absorbance of the photochemical reactant is lower than $0.1,1-10_{\lambda}^{-\varepsilon}{ }_{\lambda}^{\mathrm{CD}}$ is approximately equal to $2.303 \varepsilon_{\lambda}$ CD. Thus, Eqn. 1 can be written in the form

$$
-\left(d \mathrm{C}_{\mathrm{EE} 2} / d \mathrm{t}\right)_{\lambda}=2.303 \phi_{\lambda} \mathrm{I}_{0 \lambda} \varepsilon_{\lambda} \mathrm{CD}(\mathrm{S} / \mathrm{V}),=k_{\lambda} \mathrm{C}_{\mathrm{EE} 2}
$$


where $k_{\lambda}$ is the first-order photoreaction rate constant. In this study, the photolysis of EE2 were carried out under conditions of such low absorbance. Hence, the disappearance rate of EE2 should be pseudo-first-order with respect to EE2 concentration.

\section{A.2. Effect of Initial Concentration of EE2}

The effect of the initial concentration of EE2 on the direct photodegradation was conducted at $\mathrm{pH} 8.0$ in the concentration range between 0.20 to $1.00 \mathrm{ppm}$ of EE2. The photodegration of EE2 generally followed the pseudo-firstorder kinetics [13]. That is,

$$
\ln \left(C / C_{0}\right)=-k t
$$

where $C_{0}$ and $\mathrm{C}$ are the concentrations of EE2 at time zero and reaction time $t$ (h). $k$ is the pseudo-first-order degradation rate constant $\left(\mathrm{h}^{-1}\right)$. The photodegradation halflife $\left(t_{1 / 2}\right)$ of EE2 was calculated by

$$
t_{1 / 2}=\ln 2 / k
$$

The photodegradation rate constant increased with decreasing concentrations of EE2 under simulated sunlight (Fig. 4). The depletion half-life of EE2 varied from 1.9 to $4.1 \mathrm{~h}$ within the initial EE2 concertation range of 0.20 to $1.00 \mathrm{ppm}$. Increasing the initial concentrations of EE2 were significantly inhibited the photodegradation of EE2. In natural waters, the EE2 is commonly detected at sub-ng $\mathrm{L}^{-1}$ level or below [14]. Thus, the photodegradation half-life for EE2 in natural surface waters should be shorter than that discussed in this study.

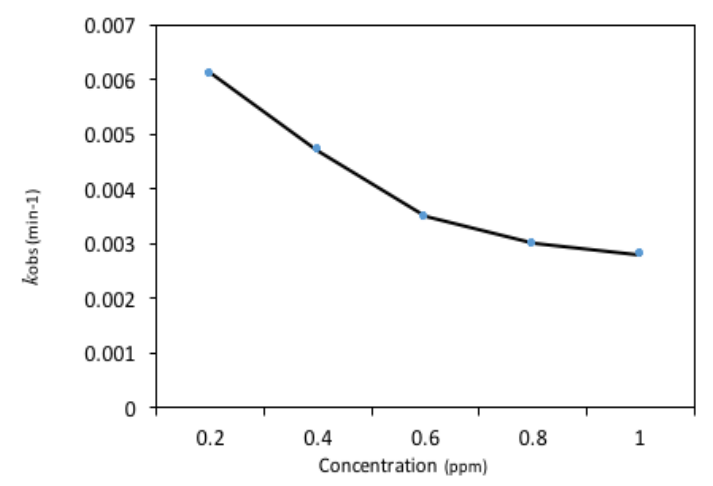

Fig. 4. The pseudo-first- order rate constant for the direct photodegradation of EE2 at different initial concentrations of EE2 under simulated light at $\mathrm{pH}=8.0$.

\section{A.3. Effect of $p H$ on the Photodegradation of EE2}

The direct photodecomposition of EE2 under simulated sunlight at various $\mathrm{pH}$ values $(3.0,8.0,9.0,10.0)$ is presented in Fig. 5. The degradation of EE2 increased with increasing $\mathrm{pH}$ in the $\mathrm{pH}$ range from 3.0 to 10.0. EE2 has a pKa value of 10.5. Thus, EE2 will start deprotonation at about $\mathrm{pH}$ 8.0, and above $\mathrm{pH} 8.0$ its deprotonated fraction increases rapidly with increasing $\mathrm{pH}$ value [15]. The deprotonation of phenolic compounds, like EE2, results in a red shift of their UV-vis absorption spectra. The red shift increased the spectrum overlap between EE2 light absorption with simulated sunlight and the photochemical reactivity of EE2 [16].

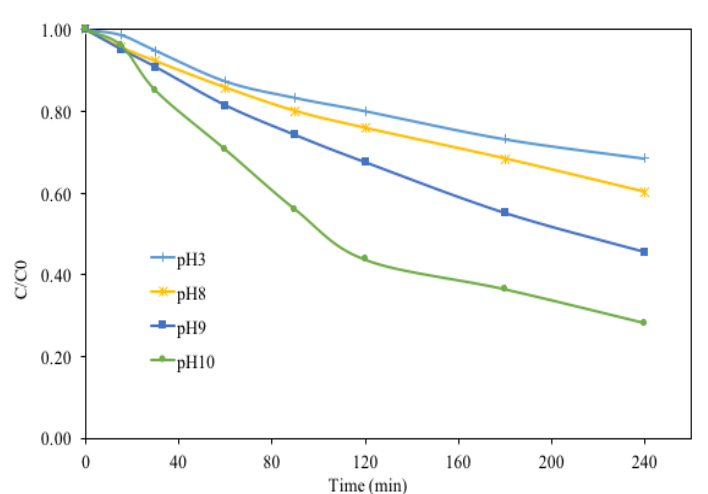

Fig. 5. Direct photodegradation of EE2 (1.0 ppm) at different $\mathrm{pH}$ values under simulated sunlight irradiation.

\section{E. Effect of Carbonate on the Photodegradation of EE2}

Carbonate $\left(\mathrm{CO}_{3}{ }^{-2}\right)$ and its conjugate acid bicarbonate $\left(\mathrm{HCO}_{3}{ }^{-2}\right)$ is a common acid-base buffering pair in natural waters [9]. These inorganic ions may affect the photodegradation of organic pollutants by scavenging $\mathrm{OH}$ and other free radicals photochemically formed,

$$
\begin{aligned}
& \mathrm{HCO}_{3}^{-}+\mathrm{HO} \cdot \quad \Rightarrow \square \mathrm{H}_{2} \mathrm{O}+\cdot \mathrm{CO}_{3}^{-} \\
& \mathrm{CO}_{3}^{-2}+\mathrm{HO} \bullet \quad \Leftrightarrow \square \mathrm{HO}^{-}+\bullet \mathrm{CO}_{3}^{-},
\end{aligned}
$$

or by neutralizing the $\mathrm{H}^{+}$ions released during the photolysis [17], [19]. To test the effects of $\mathrm{CO}_{3}{ }^{-2} / \mathrm{HCO}_{3}{ }^{-}$ions on the photodegradation of EE2, experiments were conducted in the absence or present of carbonate at concentration of 40.0 $\mu \mathrm{M}$ at $\mathrm{pH}$ values of 8.0 and 10.0. The results are presented in Fig. 6a, b. It is not surprised that carbonate ions did not significantly affect the photodegradation of EE2 since the concentration of EE2 in the photolytic solutions was low. Thus, the formation of $\mathrm{OH}$ radical and the releasing of $\mathrm{H}^{+}$ ions from the photolysis should be very limited [20], [21].

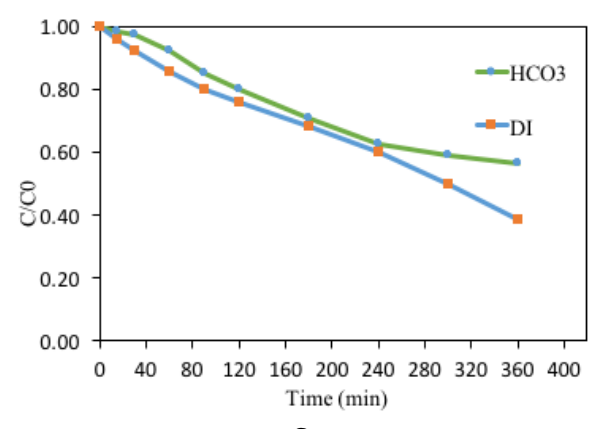

a

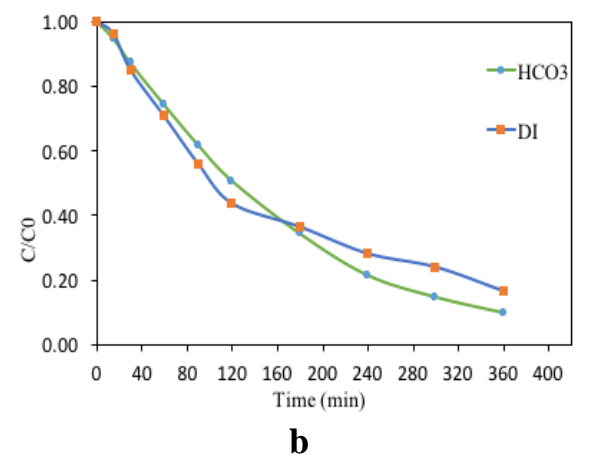

Fig. 6. Photodegaradtion of EE2 (1.0 ppm) in $40.0 \mu \mathrm{M}$ Carbonate and deionized water at $\mathrm{pH}=8.00$ (a) and at $\mathrm{pH}=10.00$ (b) under simulated light. 


\section{F. Effect of Humic Acid on the Photodegradation of EE2}

In natural water, besides direct photodegradation of EE2, a number of other organic and inorganic chromophores, such as dissolved humic acid, transition metal organic complexes, nitrate and nitrite ions, may also undergo photochemical reactions, producing reactive oxygen species, such as superoxide ions and $\mathrm{OH}$ radicals, which can further decompose EE2 and other organic pollutants [12], [13], [20].

In this study, the effects of humic acid on the photodegradation of EE2 was investigated in the presence and absence of $5.0 \mathrm{mg} / \mathrm{L}$ of humic acid at $\mathrm{pH}$ values of 7.0 , 8.0, 9.0 and 10.0. As shown in Fig. 7, the degradation of EE2 was enhanced markedly in the presence of humic acid under simulated sunlight at all $\mathrm{pH}$ values studied. This is in consistent with the earlier reports for the photosensitized degradation of other steroid estrogens E1, E2 and E3 [13]. The photodegradation of EE2 also increased with increasing solution $\mathrm{pH}$ values in the presence of humic acid.

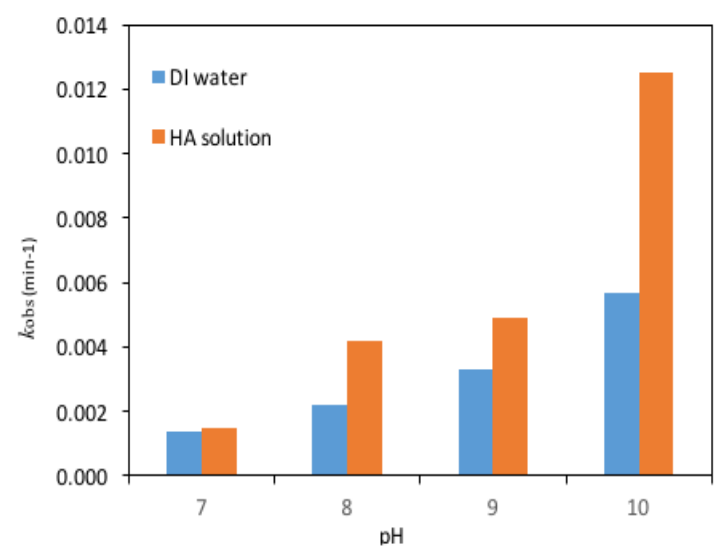

Fig. 7. Photodegradation of EE2 in the absence and presence of humic acid (HA) (5.0 mg L-1) at different $\mathrm{pH}$ values under simulated sunlight.

\section{CONCLUSIONS}

EE2 has been shown to undergo both direct and indirect photodegradation in aqueous solutions under simulated sunlight irradiation. The direct photodegradation of EE2 followed the pseudo-first-order kinetics, and the pseudofirst order reaction constant increased with decreasing initial concentration of EE2. The degradation of EE2 increased with increasing $\mathrm{pH}$ value in the $\mathrm{pH}$ range from 3.0 to 10.0 because the deprotonated EE2 has stronger UV-vis light absorption and also absorbs light at longer wavelengths. Humic acid, a common photosensitizer in marine and fresh water systems, enhanced the photodegradation of EE2 under simulated sunlight. Carbonate ions did not show significant influence on the direct photodgradation of EE2.

\section{ACKNOWLEDGEMENTS}

This work was partly supported by the US National Science Foundation under Grant OCE 0752033. The author Faten Albalawi would like to thank the Department of Chemistry at the University of Massachusetts, North Dartmouth, especially the laboratory assistants for facilitating the conduction of experiments; and the big support from Saudi Culture Mission for giving F.A scholarship to pursue her $\mathrm{PhD}$ at University of Massachusetts Dartmouth.

\section{REFERENCES}

[1] Y. Zuo, K. Zhanh, and W. Deng, "Occurrence and photochemical degradation of $17 \alpha$-ethinylestradiol in Acushnet River Estuary," Chemosphere, vol. 63, pp. 1583-1590, June 2006.

[2] K. Rao, B. Lei, N. Li, M. Ma, and Z. Wang, "Determination of estrogens and estrogenic activities in water from three rivers in Tianjin, China,” J. Environ. Sci., vol. 25, pp. 1164-1171, June 2013.

[3] R. Liu, D. O. Nelson, S. Hurley, A. Hertz, and P. Reynolds, "Residential exposure to estrogen disrupting hazardous air pollutants and breast cancer risk,” The California Teachers Study Epidemiol, vol. 26, pp. 365-373, March 2015.

[4] X. Liu, F. Wu, and N. Deng, "Photodegradation of $17 \alpha$ ethynylestradiol in aqueous solution exposed to a high-pressure mercury lamp (250 W),” Environ. Pollut, vol. 126, pp. 393-398, December 2003.

[5] Y. Zuo, K. Zhang, and S. Zhou, "Determination of estrogenic steroids and microbial and photochemical degradation of $17 \alpha$-ethinylestradiol (EE2) in lake surface water, a case study," Environ. Sci. Proc. Imp., vol. 15, pp. 1529-1535, June 2013.

[6] B. Wang, F. Dong, S. Chen, M. Chen, Y. Bai, J. Tan, F. Li, and Q. Wang, "Phenolic endocrine disrupting chemicals in an urban receiving river (Panlong river) of Yunnan-Guizhou plateau: Occurrence, bioaccumulation and sources," Ecotoxicology and Environ Safety, vol. 128, pp. 133-142, June 2016.

[7] L. A. Molot, J. J. Hudson, P. J. Dillon, and S. A. Miller, "Effect of $\mathrm{pH}$ on photo-oxidation of dissolved organic carbon by hydroxyl radicals in a coloured softwater stream,” Aquat. Sci., vol. 67, pp. 189-195, May 2005.

[8] B. Huang, X. Li, W. Sun, D. Ren, X. Li, Y. Liu, Q. Li, and X. Pan, "Occurrence, removal, and fate of progestogens, androgens, estrogens, and phenols in six sewage treatment plants around Dianchi Lake in China,” Environ. Sci. Poullut. Res., vol. 21, pp. 12898-12908, Nov 2014.

[9] D. Ren, T. Bi, S. Gao, X. Li, B. Huang, and X. Pan, "Photodegradation of $17 \alpha$-ethynylestradiol in nitrate aqueous solutions," Environmental Engineering Research, 2016.

[10] D. Vione, S. Khanra, S. C. Man, P. R. Maddigapu, R. Das, C. Arsene, R-I. Olariu, V. Maurino, and C. Minero, "Inhibition vs. enhancement of the nitrate-induced phototransformation of organic sub- strates by the $\mathrm{OH}$ scavengers bicarbonate and carbonate,” Water Res., vol. 43, pp. 4718-4728, October 2009.

[11] J. Mack and J. R. Bolton, "Photochemistry of nitrite and nitrate in aqueous solution: a review," J. Photochem. Photobiol A: Chemistry, vol. 128, pp. 1-13, November 1999.

[12] Y. Zuo, "Kinetics of photochemical/chemical cycling of iron coupled with organic substances in cloud and fog droplets," Geochim. Cosmochim. Acta, vol. 59, pp. 3123-3130, August 1995.

[13] Y. Chen, K. Zhang, and Y. Zuo, "Direct and indirect photodegradation of estriol in the presence of humic acid, nitrate and iron complexes in water solutions," Science of the Total Environment, vol. 463-464, pp. 802-809, October 2013.

[14] E. Koumaki, D. Mamais, C. Noutsopoulos, M. C. Nika, A. A. Bletsou, N. S. Thoumaidis, A. Eftaxias, and G. Stratogianni, "Degradation of emerging contaminants from water under natural sunlight: The effect of season, $\mathrm{pH}$, humic acids and nitrate and identification of photodegradation by-products,” Chemosphere, vol. 138, pp. 675-681, November 2015.

[15] D. Ren, B. Huang, T. Bin, D. Xiong, and X. Pan, "Effect of pH and dissolved oxygen on the photodegradation of $17 \alpha$-ethynylestradiol in dissolved humic acid solution,” Environmental Science: Processes Impacts, vol. 18, pp. 78-86, 2016.

[16] L. A. T. Espinoza, M. Neamtu, and F. H. Frimmel, "The effect of nitrate, Fe (III) and bicarbonate on the degradation of bisphenol A by simulated solar UV-irradiation,” Water Res., vol. 41, pp. 4479-4487, November 2007.

[17] V. K. Gupta, R. Jain, A. Mittal, T. A. Saleh, A. Nayak, S. Agarwal, and S. Sikarwar, "Photo-catalytic degradation of toxic dye amaranth on TiO2/UV in aqueous suspensions,” Mater. Sci. Eng. C, vol. 32, pp.12-17, January 2012.

[18] Y. Zuo and Y. Deng, "The near-UV absorption constants for nitrite ion in aqueous solution,” Chemosphere, vol.36, pp.181-188, 1998.

[19] F. Yu, X. Pan, and B. Wang, "Determination of four phenolic endocrine disrupting chemicals in Dianchi Lake, China," Intern. J. Environ. Anal. Chem., vol. 92, pp.1532-1545, November 2011.

[20] Y. Zuo and J. Hoigné, "Evidence for photochemical formation of $\mathrm{H}_{2} \mathrm{O}_{2}$ and oxidation of $\mathrm{SO}_{2}$ in authentic fog water," Science, vol. 260, pp. 71-73, Apr 1993.

[21] E. de Laurentiis, S. Buoso, V. Maurino, C. Minero, and D. Vione, "Optical and photochemical characterization of chromophoric 
dissolved organic matter from lakes in terra nova bay, antarctica. evidence of considerable photoreactivity in an extreme environment," Environ. Sci. Techno, vol. 47, no. 24, pp. 14089-14098, November 2013.

Faten Albalawi has acquired a bachelor degree in chemistry from Tabouk University, a master degree in chemical manufacturing management from Murray State University. She currently is a Ph.D student in analytical chemistry and environmental chemistry at the University of Massachusetts Dartmouth. Her research interests are analytical chemistry and environmental chemistry. She is working in professor Yuegang Zuo’s lab.

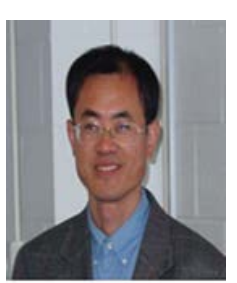

Yuegang Zuo is a professor at the University of Massachusetts Dartmouth. He obtained his B.S. from Wuhan University in 1982, M.S. from Chinese Academy of Science in 1984, and Ph.D from ETH Zurich in 1992. His research interests include analytical chemistry, environmental chemistry, marine chemistry, and photochemical transformation of organic and inorganic substances in the environment. 